\title{
Nail-Patella syndrome: a case report and anesthetic implications
}

\section{[L'ostéo-onychodysostose : présentation de cas et implications anesthésiques]}

Trevor A. Hennessey MD, ${ }^{*}$ Steven B. Backman MD PhD, ${ }^{*}$ Sarkis H. Meterissian MD MSc, $†$

Thomas Schricker MD PhD*

Purpose: To report a case of asystole during combined epidural and general anesthesia occurring in a patient with Nail-Patella syndrome (NPS), and to review the management and anesthetic implications of this rare genetic syndrome.

Clinical features: A 64-yr-old male with NPS, renal impairment and coronary artery disease presented for right hemicolectomy for colon cancer. Following initiation of surgery and during insertion of a nasogastric tube there was sudden loss of the patient's pulse oxymetry, and arterial pressure waveforms with an asystolic electrocardiogram signal. Atropine $0.6 \mathrm{mg}$ iv was administered and after an asystolic period of 20-30 sec, myocardial activity commenced at 110 beats $\mathrm{min}^{-1}$ with return of normal vital signs and no further sequelae.

Conclusions: Nail-Patella syndrome can present with an array of anomalies that may be associated with perioperative complications. Glaucoma, nephropathy, vasomotor dysfunction, fragile teeth, abnormal muscle, skeletal and nerve anatomy as well as involvement of the central and/or peripheral nervous systems are common findings. In this setting it is postulated that a vasovagal reflex from esophageal stimulation by nasogastric tube placement may have caused the asystolic event. This response could have been exaggerated by the sympatholytic combination of neuraxial block, preoperative beta-blockade, and potential autonomic dysfunction secondary to NPS. Awareness of this uncommon disease and its presentation may serve to caution the anesthesiologist regarding the perioperative implications of patients with this syndrome.

CAN J ANESTH 2007 / 54: 10 / pp 835-839
Objectif : Présenter un cas d'asystolie lors d'une anesthésie péridurale et générale combinée survenue chez un patient souffrant d'ostéo-onychodysostose (NPS - Nail-Patella syndrome), et passer en revue la prise en charge et les implications anesthésiques de ce syndrome génétique rare.

Éléments cliniques : Un homme âgé de 64 ans, souffrant de NPS, d'insuffisance rénale et de maladie coronarienne, s'est présenté pour une hémicolectomie droite suite au diagnostic d'un cancer du colon. Peu après le début de la chirurgie et pendant l'insertion d'une sonde naso-gastrique, il y a eu une perte subite du signal de l'oxymètre et des courbes de pression artérielle avec asystolie. De l'atropine 0,6 mg en iv a été administrée et après une période d'asystolie de 20-30 sec, l'activité myocardique a débuté à 110 battements $\mathrm{min}^{-1}$ avec un retour à des signes vitaux normaux et aucune séquelle ultérieure.

Conclusion : L'ostéo-onychodysostose peut survenir accompagnée d'une série d'anomalies qui peuvent être associées à des complications périopératoires. Un glaucome, une néphropathie, une dysfonction vasomotrice, une dentition fragile, des muscles anormaux, une anatomie squelettique et nerveuse ainsi que des atteintes du système nerveux central et/ou périphérique sont régulièrement observés. Dans ce contexte, nous pensons qu'un réflexe vasovagal provoqué par une stimulation oesophagienne lors du positionnement de la sonde naso-gastrique pourrait avoir causé l'asystolie. Cette réaction a peut-être été exacerbée par la combinaison sympatholytique d'un bloc neuraxial, d'un bêta-blocage préopératoire et d'une dysfonction autonome potentielle secondaire à la NPS. Une connaissance de cette maladie peu courante et de sa présentation pourrait prévenir l'anesthésiste des implications périopératoires de patients souffrant de ce syndrome.

From the Department of Anesthesia, ${ }^{*}$ and Surgery, $†$ Royal Victoria Hospital, McGill University Health Center, Montreal, Quebec, Canada.

Address correspondence to: Dr. Thomas Schricker, Department of Anaesthesia, Royal Victoria Hospital, 687 Pine Avenue West, Rm. C5.20, Montreal, Quebec H3A 1Al, Canada. Phone: 514-934-1934, ext. 34883; Fax: 514-843-1698; E-mail: thomas.schricker@mcgill.ca Funding: No sources of funding other than standard departmental and residency salaries were used.

Conflict of interest: The authors do not have any financial or commercial interest in the subject matter, materials or equipment discussed or in competing materials.

Accepted for publication May 29, 2007.

Revision accepted July 16, 2007. 


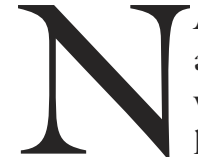

AIL-PATELLA syndrome (NPS) is an autosomal dominant inherited condition with an estimated incidence of 1:50,000 live births. ${ }^{1}$ Also known as Iliac Horn syndrome, Hereditary Onychoostedysplasia, Fong Disease or Turner-Kiser syndrome, the mutated gene associated with this condition (LMX1B) is located on chromosome 9q34. Initially described in 1948, this disorder is characterized by the classical tetrad of nail and elbow dysplasia, patellar aplasia or hypoplasia, and iliac horns. ${ }^{2}$ Other features commonly observed include ophthalmologic (open-angle glaucoma, cloverleaf dark pigmentation of the iris, micro and sclerocornea, and cataracts) and renal pathology. Though not invariably, patients afflicted with NPS may demonstrate peripheral polyneuropathy and vasomotor dysfunction, suggesting involvement of the central and/or peripheral nervous systems. ${ }^{3,4}$ While NPS patients have undergone a variety of surgical procedures to address their associated disorders, there are no reports describing their anesthetic management.

We describe the operative course for a NPS patient who underwent colorectal surgery for cancer and discuss the anesthetic implications of this syndrome. Consent was obtained for disclosure of this case.

\section{Case report}

A 64-yr-old male with NPS and cancer of the colon presented for right hemicolectomy in 2005. In addition to the pathognomonic tetrad the patient demonstrated open-angle glaucoma and renal impairment reflected by moderate proteinuria, creatinine clearance of $85 \mathrm{~mL} \cdot \mathrm{min}^{-1}$, serum creatinine of $106 \mu \mathrm{mol} \cdot \mathrm{L}^{-1}$ and serum urea of $10.3 \mathrm{mmol} \cdot \mathrm{L}^{-1}$. He denied neurological symptoms including upper or lower extremity motor or sensory deficits. Complete blood count, electrolytes and coagulation studies were within normal limits. The patient's medical history was significant for a myocardial infarction in 1991, arterial hypertension, hypercholesterolemia, benign prostatic hypertrophy and a remote submandibular gland excision. Coronary angiography at the time of the patient's myocardial infarction revealed a 100\% occluded right coronary artery. An echocardiogram performed in 2000 showed a mildly reduced ejection fraction with no wall motion abnormalities. An exercise stress test conducted preoperatively was normal and the electrocardiogram showed normal sinus rhythm at a rate of 76 beats. $\mathrm{min}^{-1}$. The patient's daily medications included bisoprolol $5 \mathrm{mg}$, ramipril $10 \mathrm{mg}$, simvastatin $40 \mathrm{mg}$, tamsulosin $0.4 \mathrm{mg}$, replavite, dorzolamide/timolol and latanoprost eye drops.

Anesthetic management consisted of combined general and epidural anesthesia. After pre-medication with midazolam $1.5 \mathrm{mg}$ administered intravenously via a $16 \mathrm{G}$ catheter inserted into an upper extremity vein, an epidural catheter was inserted at the T10-11 level. A test dose of $3 \mathrm{~mL}$ lidocaine $2 \%$ was injected to exclude intrathecal catheter placement. Five millilitres of bupivacaine $0.5 \%$ were then injected, resulting in a bilateral sensory block to T5 Neuraxial anesthesia was maintained by $5 \mathrm{~mL}$ boluses of bupivacaine $0.25 \%$ every $30 \mathrm{~min}$. Loss of consciousness followed administration of propofol $150 \mathrm{mg} i v$ and fentanyl 150 $\mu \mathrm{g} i \mathrm{v}$. Tracheal intubation was facilitated by muscle paralysis produced with rocuronium $50 \mathrm{mg} i \mathrm{v}$ and the patient's lungs were ventilated using oxygen-enriched nitrous oxide $\left(\mathrm{F}_{\mathrm{I}} \mathrm{O}_{2}=0.35\right)$. General anesthesia was maintained with isoflurane (end-tidal concentrations $0.3-0.4 \%)$. The patient was covered with a warming blanket and intravenous fluids $\left(6 \mathrm{~mL} \cdot \mathrm{kg}^{-1} \cdot \mathrm{hr}^{-1}\right)$ were warmed. Catheters were inserted into the right radial artery and internal jugular vein to continuously monitor arterial and central venous pressures, respectively. Neutral positioning of the upper and lower extremities was achieved with careful placement of limbs, and attention was given to padding of pressure points.

Prior to surgical incision, two boluses of $0.1 \mathrm{mg}$ phenylephrine were required to maintain the blood pressure between 90 and $120 \mathrm{mmHg}$ systolic. The patient's heart rate $\left(60-70\right.$ beats. $\left.\mathrm{min}^{-1}\right)$ and central venous pressure $(10-12 \mathrm{mmHg})$ were stable. Following the start of surgery, a nasogastric tube was inserted through the patient's right nostril. During this maneuver, there was a sudden loss of the patient's pulse oxymetry, and arterial pressure waveforms and an asystolic electrocardiogram signal (lead II) was observed. Pre-drawn atropine $0.6 \mathrm{mg} i v$ was immediately administered followed by a bolus of normal saline, and following an asystolic period of approximately 20-30 sec but before chest compressions could be initiated myocardial activity commenced at 110 beats $\mathrm{min}^{-1}$ (normal sinus rhythm). At this time, blood pressure measured $110 / 40 \mathrm{mmHg}$ and was accompanied by return of pulse oxymetry and arterial pressure waveforms. The surgery proceeded uneventfully, and for the remainder of the case the patient's vital signs were stable.

Following cessation of administration of general anesthesia, and reversal of muscle paralysis (neostigmine $2.5 \mathrm{mg}$, glycopyrrolate $0.6 \mathrm{mg}$ ), the patient was extubated in the operating theatre. The postoperative course was uneventful. Upon disclosure of the episode of asystole, the patient admitted to two prior episodes of syncope during times of emotional stress, one of which required cardiopulmonary resuscitation by a neighbour who happened to be a cardiologist in our institution and who confirmed the event. 


\section{Discussion}

Although there are reports concerning surgical management of patients with NPS ${ }^{5-11}$ the anesthesia literature has heretofore not addressed this disorder. A distinguishing feature of the intraoperative course, as described in this report, is the transient episode of asystole following insertion of a nasogastric tube that must be addressed in the context of a previously undisclosed history of syncope.

Asystole upon placement of a nasogastric tube has not been described previously. In fact, modest tachycardia and hypertension are typically observed with this procedure, ${ }^{12}$ and would be especially anticipated in a lightly-anesthetized patient as described in this report. However cardiac arrest during deglutition, and both bradycardia and termination of paroxysmal tachycardia associated with placement of a nasogastric tube have been reported. ${ }^{13-15}$ Bradycardia may also be associated with upper gastrointestinal endoscopy. ${ }^{16}$ Although the precise neural pathway mediating these responses is unclear, a vasovagal reflex involving visceral afferent activation of cardioinhibitory centres in the brainstem has been proposed. ${ }^{15}$ By analogy, it is conceivable that stimulation of afferent vagal fibres during the esophageal passage of the nasogastric tube triggered the cardiac arrest in our patient.

It is anticipated, moreover, that this response could be exaggerated by the sympatholytic combination of neuraxial block and preoperative use of beta-blocker medication.

Following the initial reports from the closed claims database in the US in 1987 severe bradycardia has been recognized as a complication of epidural anesthesia with an estimated incidence of 1.0-6.4:10,000. Risk factors for asystole under neuraxial anesthesia include age less than $60 \mathrm{yr}$, baseline heart rate less than 60 beats. $\mathrm{min}^{-1}$, concurrent use of beta-blocking agents, male gender, ASA status I, sensory level blockade above $\mathrm{T}_{6}$ and a prolonged PR interval. Various pathogenetic mechanisms have been proposed such as blockade of cardio-accelerator fibres, inhibition of low pressure baroreceptor in the atrium and vena cava and sympathetic efferents with resulting decreased venous blood flow and the Bezold-Jarisch reflex. ${ }^{17}$

The patient's previous history of syncope suggests a baseline of sinus node dysfunction that may be associated with his coronary artery disease including an occluded right coronary artery. The potential for autonomic dysfunction in a patient with NPS must also be considered. The mutated gene associated with this condition (LMXIB) has been linked with abnormalities in a variety of structures in the central nervous system (CNS) including mesencephalic dopaminergic and hindbrain serotonergic neuron development. ${ }^{4}$ It has been known for some time that sympathetic preganglionic neurons in the intermediolateral nucleus of the spinal cord receive prominent catecholaminergic and serotonergic input from the brain stem, and so the CNS abnormalities associated with NPS could affect autonomic cardiovascular outflow. ${ }^{18}$ In fact, patients with NPS may demonstrate symptoms suggestive of vasomotor dysfunction such as cold extremities and Raynaud's phenomenon. ${ }^{3}$ Bradycardia and asystole have been reported in a patient with NPS and coexisting mitochondrial myopathy and left ventricular hypertrabeculation/noncompaction, however no mention of noncompaction was noted on the patient's report of his previous echocardiogram though the images were no longer available for review. ${ }^{19}$ Thus, it is recommended to obtain, preoperatively, a detailed cardiac history in NPS patients, with specific attention to symptoms suggestive of dysrhythmias. Consultation with a cardiologist may be considered, including request for Holter monitoring and echocardiography.

Management of this asystolic event was in accordance with that suggested within the literature. Should a perfusing rhythm have not been obtained following the administration of atropine, cardiopulmonary resuscitation and the early use of epinephrine would have been utilized as this has been shown to improve survival in similar situations involving cardiac arrest under neuraxial anesthesia. ${ }^{17,20}$

Mutated LMXIB gene expression has also been linked to developmental abnormalities in the dorsal horn of the spinal cord. ${ }^{4}$ This is thought to mediate the neurological symptoms reported by many NPS patients including episodic numbness and paresthesiae, and decreased perception of pain and temperature in the upper and lower extremities. ${ }^{3,4}$ During the preoperative assessment, a detailed history of any neurological abnormality should be sought with particular attention to sensory deficits in the extremities. Both surgeons and anesthesiologists should be aware of the possibility of abnormal muscle and nerve insertions outside of the normal anatomical position and thus preoperative magnetic resonance imaging assessments may be indicated depending on the planned procedures. These abnormalities require careful attention to patient positioning of extremities and padding of weight bearing surfaces. In a review of 123 patients with NPS, $55 \%$ reported chronic back pain with increased lumbar lordosis as well as scoliosis noted in $47 \%$ and $23 \%$ of patients respectively. Rarer axial skeletal abnormalities included dural ectasia and spina bifida occulta. ${ }^{3}$ Consultation with a neurologist may be prudent, particularly if major conduction anes- 
thesia involving an effected limb is contemplated and careful spine assessment should be undertaken prior to neuraxial blockade. Medico-legal considerations notwithstanding, there is as yet no reason to dismiss these techniques of anesthesia in the NPS patient.

In the rodent model of NPS, although LMXIB gene deficiency is typically associated with a variety of skeletal abnormalities involving nails, bone tendons and ligaments, an effect on the migration of motor axons of the lateral motor column is reported. ${ }^{4}$ Thus, depolarizing muscle relaxants such as succinylcholine should be used cautiously, if at all. The association of NPS with weakened tooth structure ${ }^{3}$ mandates particular care during intubation, and so warrants a frank preoperative discussion concerning the risk of damage to the teeth.

Open-angle glaucoma appears to also be associated with NPS. ${ }^{21}$ Patients with glaucoma may be at risk for retinal vascular thrombosis. ${ }^{22}$ Topical eye drops may also have systemic effects. ${ }^{23}$ Recommendations include discontinuing cholinesterase inhibitors four to six weeks prior to surgery while continuing other glaucoma medications and if on acetazolamide to check electrolytes. Avoidance of anemia, hypotension and meticulous care in positioning the patient should prone positioning be required may all help to maintain retinal perfusion.

Patients are at risk for a form of nephropathy resembling glomerulonephritis with involvement ranging from asymptomatic proteinuria to full nephrotic syndrome and end-stage renal disease. Assessment for renal impairment should thus be undertaken preoperatively with baseline measurement of serum electrolytes and creatinine with calculation of creatinine clearance. Drug doses, intervals and fluid infusion rates should be adjusted accordingly.

The LMXIB gene has also been developmentally linked to gastrointestinal development and function in both chicken and $C$ elegans animal models. ${ }^{24,25}$ Bowel symptoms such as chronic constipation have been reported by $18 \%$ of NPS patients in one case series. ${ }^{3}$ Therefore the generous use of stool softeners and related agents for NPS patients receiving intraoperative and postoperative opioids would be prudent.

In conclusion, while NPS has been identified for over 50 years, the anesthetic course of a patient with this disorder has never been reported. We describe an unusual incident of asystole following insertion of a nasogastric tube in a patient with NPS with a previously undisclosed history of syncope undergoing abdominal surgery under combined regional/general anesthesia. Possible underlying mechanisms mediating this response are discussed, and anesthetic consider- ations relating to the multi-organ system involvement of a patient with NPS are reviewed.

\section{References}

1 Bongers EM, Gubler MC, Knoers NV. Nail-patella syndrome. Overview on clinical and molecular findings. Pediatr Nephrol 2002; 17: 703-12.

2 Mino R, Mino V, Livingstone R. Osseous dysplasia and dystrophy of the nail: review of the literature and report of a case. Am J Roentenol 2006; 60: 633-41.

3 Sweeney E, Fryer A, Mountford R, Green A, McIntosh I. Nail patella syndrome: a review of the phenotype aided by developmental biology. J Med Genet 2003; 40 : 153-62

4 McIntosh I, Dunston JA, Liu J, Hoover-Fong JE, Sweeney $E$. Nail patella syndrome revisited: 50 years after linkage. Ann Hum Genet 2005; 69: 349-63.

5 Guidera KJ, Satterwhite Y, Ogden JA, Pugh L, Ganey $T$. Nail patella syndrome: a review of 44 orthopaedic patients. J Pediatr Orthop 1991; 11: 737-42.

6 Juma AH. Nail-patella syndrome in Saudi Arabia with new features and surgical procedures: the first described study. MedGenMed 2004; 6: 6.

7 Kumar A, Iqbal MJ, Ali MS. Separation of bipartite patella in nail-patella syndrome: a case report. Knee 1999; 6: 67-9.

8 Lachiewicz PF, Herndon CD. Total knee arthroplasty for osteoarthritis in hereditary onycho-osteodysplasia (nail-patella syndrome): a case report. Am J Orthop 1997; 26: 129-30.

9 Lazzeri S, Nori G, Matocci GP, Di Filippo P. Hereditary osteo-onychodysplasia or nail-patella syndrome: description of one case and literature review. J Orthopaed Traumatol 2005; 6: 105-9.

10 Marumo K, Fujii K, Tanaka T, Takeuchi H, Saito H, Koyano $\Upsilon$. Surgical management of congenital permanent dislocation of the patella in nail patella syndrome by Stanisavljevic procedure. J Orthop Sci 1999; 4: 446-9.

11 Song HR, Cho SH, Koo KH, Jung ST, Shin HS. Treatment of antecubital pterygium in the nail-patella syndrome. J Ped Orthop B 1998; 7: 27-31.

12 Fassoulaki A, Athanassion E. Cardiovascular responses to the insertion of nasogastric tubes during general anesthesia. Can Anaesth Soc J 1985; 32: 651-3.

13 Gupta A, Lennmarken C, Lemming D, Lindqvist J. Termination of paroxysmal supraventricular tachycardia with a nasogastric tube - a case report. Acta Anaesthesiol Scand 1991; 35: 786-7.

14 Magadle R, Weiner P, Sozkover A, Berar-Yanay N. Recurrent deglutition syncope. Isr Med Assoc J 2001; 3: 222-3.

15 Cherukuri S, Gardner GM. Deglutition syncope. 
Otolaryngol Head Neck Surg 2004; 130: 145-7.

16 Triandaf I, Stanciu C, Solomon M, Grauer M, Untu A. Continuous electrocardiographic monitoring during upper gastrointestinal endoscopy. Med Interne 1978; 16: $43-5$.

17 Pollard JB. Cardiac arrest during spinal anesthesia: common mechanisms and strategies for prevention. Anesth Analg 2001; 92: 252-6.

18 Dahlstrom A, Fuxe K. Evidence for the existence of monoamine neurons in the central nervous system. II. Experimentally induced changes in the intraneuronal amine levels of bulbospinal neuron systems. Acta Physiol Scand 1965; SUPPL 247:1-36.

19 Finsterer J, Stollberger C, Steger C, Cozzarini W. Complete heart block associated with noncompaction, nail-patella syndrome, and mitochondrial myopathy. J Electrocardiol 2007; 40: 352-4.

20 Kopp SL, Horlocker TT, Warner ME, et al. Cardiac arrest during neuraxial anesthesia: frequency and predisposing factors associated with survival. Anesth Analg 2005; 100: 855-65.

21 Lichter PR, Richards JF, Downs CA, Stringham HM, Boebnke M, Farley FA. Cosegregation of openangle glaucoma and the nail-patella syndrome. Am J Ophthalmol 1997; 124: 506-15.
22 Barash PG. Clinical Anesthesia, $5^{\text {th }}$ Ed. Philadelphia: Lippincott Williams \& Wilkins; 2006.

23 McGoldrick KE. Ocular drugs and anesthesia. Int Anesthesiol Clin 1990; 28: 72-7.

24 Riddle RD, Ensini M, Nelson C, Tsuchida T, Jessell TM, Tabin C. Induction of the LIM homeobox gene Lmxl by WNT7a establishes dorsoventral pattern in the vertebrate limb. Cell 1995; 83: 631-40.

25 Hobert O, Tessmar K, Ruvkun G. The Caenorhabditis elegans lim-6 LIM homeobox gene regulates neurite outgrowth and function of particular GABAergic neurons. Development 1999; 126: 1547-62.

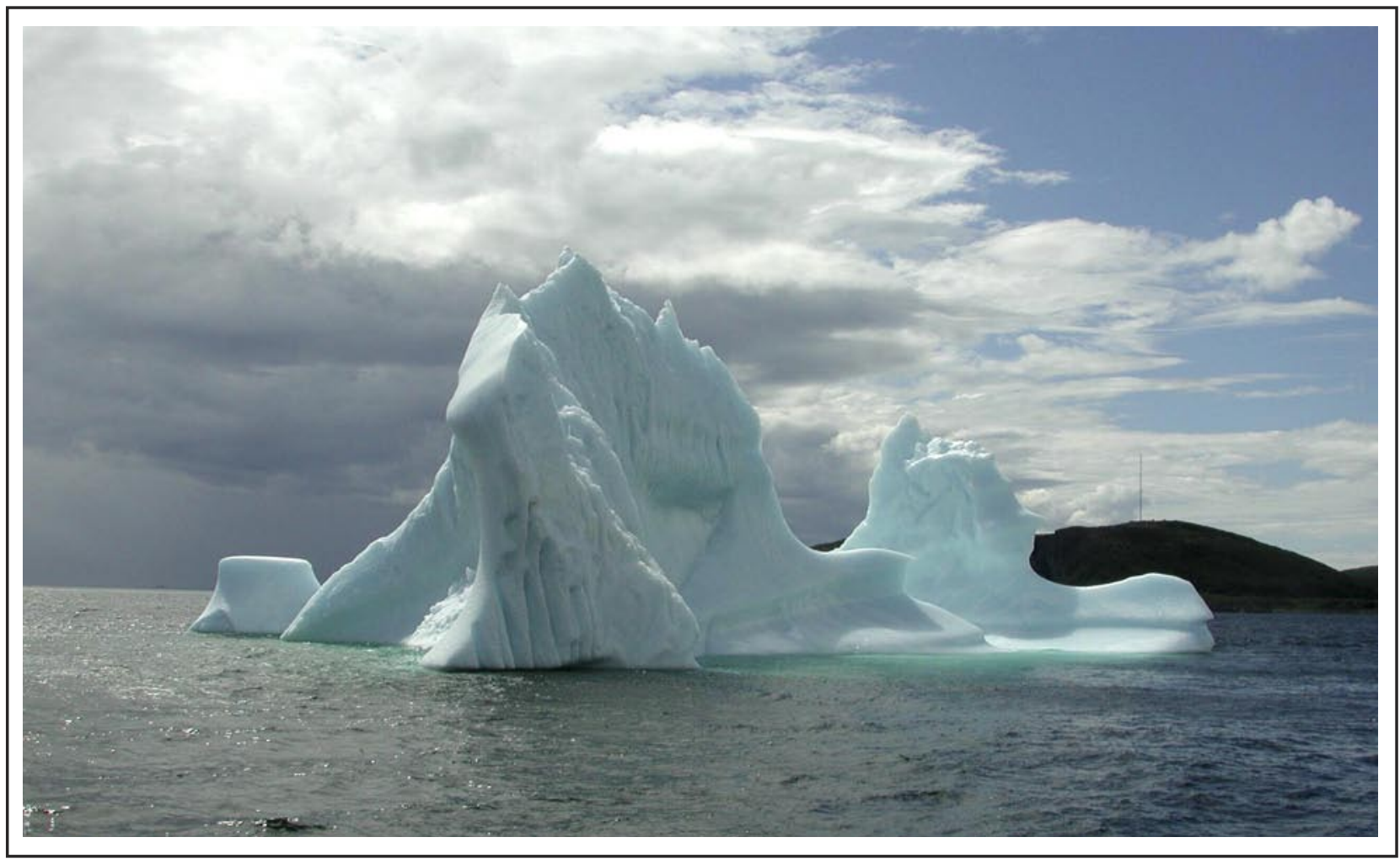

Port Anthony, Northern Peninsula - Newfoundland 